\title{
THE TEMPERAMENT AND CHARACTER TRAITS IN PATIENTS WITH MAJOR DEPRESSIVE DISORDER AND BIPOLAR AFFECTIVE DISORDER WITH AND WITHOUT SUICIDE ATTEMPT
}

\author{
Anamarija Petek Erić ${ }^{1,2}$, Ivan Erić ${ }^{3}$, Mario Ćurković ${ }^{4}$, Katarina Dodig-Ćurković ${ }^{2,5}$, \\ Kristina Kralik ${ }^{6}$, Vlatka Kovač ${ }^{5}$ \& Pavo Filaković ${ }^{2}$ \\ ${ }^{1}$ Department of Psychiatry, University Hospital Centre Osijek, Osijek, Croatia \\ ${ }^{2}$ Department of Psychiatry and Psychological Medicine, Josip Juraj Strossmayer University of Osijek, \\ Medical School Osijek, Osijek, Croatia \\ ${ }^{3}$ Department of Surgery, University Hospital Centre Osijek, Medical School Osijek, \\ Josip Juraj Strossmayer University Osijek, Osijek, Croatia \\ ${ }^{4}$ Department of Family Medicine, Josip Juraj Strossmayer Univeristy of Osijek, Medical School Osijek, Osijek, Croatia \\ ${ }^{5}$ Department of Child and Adolescent Psychiatry, University Hospital Centre Osijek, Osijek, Croatia \\ ${ }^{6}$ Department of Biophysics, Medical Statistics and Medical Informatics, Josip Juraj Strossmayer University of Osijek, \\ Medical School Osijek, Osijek, Croatia
}

received: 28.11.2016;

revised: 1.2.2017;

accepted: 28.2 .2017

\section{SUMMARY}

Background: Suicide and mood disorders (especially major depressive disorder (MDD) and bipolar affective disorder (BD)) represent a significant global health burden. Major depressive disorder and bipolar affective disorder have been associated with increased risk for suicide. Some specific suicide risk factors might be found in underlying individual personality traits. Specific personality features may predispose an individual to mood disorders (MDD or BD) hence increased suicide risk. The specificity of this research is in the assessment of personality features during the acute phase of illness immediately after suicide attempt which resulted in psychiatric inpatient treatment.

Subjects and methods: The study included 119 unrelated Caucasian participants with MDD-severe depressive episode without psychotic symptoms $(M D D)$ and BD-severe depressive episode without psychotic symptoms (BD-sDE). Both groups of patients with $M D D$ and $B D-s D E$ were divided into the suicide attempters and non-suicidal group. The diagnoses of the severe depressive episode without psychotic symptoms in major depressive disorder (MDD; F32.2) and bipolar disorder (BD-sDE; F31.4) were made according to ICD-10 (WHO 1992) diagnostic criteria. Methods of suicide attempts were also assessed according to ICD-10 and a self-report questionnaire, the Temperament and Character Inventory (TCI) was applied.

Results: The participants who exhibited suicide attempt had significantly higher scores on harm-avoidance $(H A)(p<0.001)$, significantly lower score on persistence $(P S)(p=0.037)$ and lower score, however not statistically significant, on novelty-seeking (NS) $(p=0.319)$ regarding temperament dimensions. In character dimensions, the patients with suicidal attempt had significantly lower scores on self-directedness $(S D)(p<0.001)$ and significantly lower scores on cooperativeness $(C O)(p=0.001)$.

Conclusion: Patients who had suicide attempt may have some significantly different personality traits than non-suicidal patients with mood disorders. The combination of high harm-avoidance (HA) and low self-directedness (SD) may be specific for depressive episode while the combination of high HA, novelty-seeking (NS), and self-transcendence (ST) with low SD may be related to suicide attempts during the depressive episode in bipolar disorder. The novelty-seeking (NS), self-transcendence (ST) and self-directedness (SD) may be specific for suicidal group of bipolar patients.

Key words: major depressive disorder - bipolar disorder - suicide attempt - temperament and character

$$
* * * * *
$$

\section{INTRODUCTION}

Suicide and mood disorders (especially major depressive disorder and bipolar affective disorder) represent a significant global health burden (WHO, Mental Health Atlas 2014). According to the World Health Organization (WHO), it is estimated that depression affects 350 million people (WHO, Global Health Estimates 2013). Major depressive disorder (MDD) is often chronic, recurring and gradually results in reducing overall individual functioning. Therefore, depression is also a leading cause of disability worldwide, for both males and females, due to total years lost for disability
(WHO, Mental Health Action Plan 2013). Bipolar disorder (BD), is common severe and persistent mental disorder which is characterized by manic, depressive, and mixed episodes and is associated with long-term cognitive and functional impairment (Connolly \& Thase 2011, Clemente et al. 2015). The lifelong prevalence rate of bipolar disorder is $0.3-1.5 \%$ (Yutzy et al. 2012). The life-expectancy has been found to be much shorter in patients with bipolar affective disorder (Laursen 2011). Both above mentioned disorders, have been associated with increased risk for suicide (Rihmer 2007). Patients with BD have a suicide rate 30 times higher than the general population and $25-50 \%$ of these 
patients will attempt suicide once in their lifetime (Marangell et al. 2006). Fifteen percent of those who attempted suicide eventually make complete suicide (Izci et al. 2016). Although MDD has an overall negative health impact and is associated with morbidity which is hard to determine, its lethality becomes measurable through a perspective of completed suicide (Harwitz \& Ravizza 2000). Furthermore, as many as two-thirds of people with depression reports suicidal ideation, $10-15 \%$ commit suicide and $60-70 \%$ suicide victims have had severe depression before completed suicide (Woo et al. 2014). Regardless the decline in suicide mortality, in majority of countries with high baseline suicide rates, suicidal behavior still manifests among patients with mood disorders in state-dependent order (Latalova et al. 2014, Rihmer et al. 2006, Suominen et al. 2004).

\section{Mood disorders, suicidal behavior and personality traits}

The term multicausal underlays the etiology of mood disorders and suicidal behavior. Both pathological entities consist out of a variety of possible factors involved in their appearance and development. The suicide risk factors in mood disorders can be divided into proximal and distal. The distal factors (one's unrelated to current or past mood episodes) are as follows: epigenetic factors, early onset of mood disorders, family history of suicide, alcohol/substance abuse, adverse early life situations, permanent adverse life situations (isolation, unemployment) and personality traits. The proximal factors (related to current or past mood episodes) include: hopelessness, impulsiveness, suicidal ideation, psychopathology and recent life events (Turecki et al. 2012, Undurraga et al. 2012, Rudd et al. 2006, Sokero et al. 2005). Even with an effort and recognition through clinical screening, of various suicide risk factors in MDD and $\mathrm{BD}$, the prediction of suicidal behavior/attempts is still predominantly undeterminable with frequent falsepositive and -negative findings (Ekinci et al. 2012, Conrad et al. 2009). In the vast amount of possible suicide risk factors, more specific one's might be found in the underlying individual personality traits. Personality, in general, refers to individual differences in characteristic patterns of thinking, feeling and consequently behaviour (McAdams \& Bradley 2010). Personality features constitute a vital part of stressdiathesis model for suicidal behavior hence it is important to understand which of these features may be linked to suicidal behavior and whether suicidality emerges in the context of a duration of the psychiatric disorder or is a situation-oriented process (Mann 2013, Kampman \& Poutanen 2011). As for suicide-oriented factors, specific personality features may predispose an individual to mood disorders (MDD or BD) hence increased suicide risk. Personality can be modified after the onset of the depressive episode; personality can affect the clinical presentation of a depressive episode, and the depressive personality can be considered as a subtype of mood disorder (Richter et al. 2000, Akiskal et al. 1983). Also, it has been shown that vulnerability to suicide is partly genetically determined (Brent \& Mann 2005). Apart from non-genetic factors, heritable factors in the suicide diathesis account for $\sim 45 \%$ of this variance and based on twin studies, about $40 \%$ of personality variance is determined by genetic factors (Pawlak et al. 2016, Statham et al. 1998). The Cloninger's psychobiological model of temperament and character evaluates seven higher order personality or behaviour traits. These include four higher order temperament (novelty-seeking (NS); harm-avoidance (HA); reward dependence (RD) and persistence (PS)) traits and three higher order character (self-directedness (SD); cooperativeness (CO); selftranscendence (ST)) traits (Cloninger et al. 1993). The temperament dimensions correspond to the underlying genetic structure of personality meaning these four temperament dimensions are genetically homogeneous and independent. Contrary to temperament dimension, the character refers to self-concepts and individual differences in goals and values which affect intentions, opinionated choices and the meaning of what is experienced in life. Character differences are influenced by sociocultural learning and maturation (Cloninger et al. 1994). Heretofore, different studies were performed using the Temperament and Character Inventory (TCI) to investigate personality factors associated with suicidal behavior and mood disorders (MDD and BD). These studies were predominantly focused on correlation between euthymic states and certain aspect of mood disorder (major depressive disorder, bipolar disorder - I and II, relation to past mood episodes) and specific aspects of suicidal behaviour (suicide ideation, impulsivity, relation to previous suicide attempts, genetic and family background) (Jylhä et al. 2016, Karam et al. 2015, de Abreu et al. 2009, Calati et al. 2008). However, there is quite sparse data concerning actual suicide attempts in mood disorders (MDD and $\mathrm{BD}$ ) during the severe depressive episode (without psychotic symptoms) and personality features (Camarena et al. 2014, Pawlak et al. 2013). In this study, we aimed to determine specific personality traits, measured with TCI, among patients with suicide attempt during the severe depressive episode without psychotic symptoms in MDD and BD (according to International Statistical Classification of Diseases and Related Health Problems $10^{\text {th }}$ Revision (ICD-10), World Health Organization (WHO)). The specificity of this research is in assessment of personality features during acute phase of illness (MDD or BD) immediately thereafter suicide attempt which resulted in psychiatric inpatient treatment. 


\section{SUBJECTS AND METHODS}

The research included 119 unrelated Caucasian participants with MDD-severe depressive episode without psychotic symptoms (MDD) and BD-severe depressive episode without psychotic symptoms (BD-sDE). The sample consisted of $81(68 \%)$ female and 38 (32\%) male patients. The patients were recruited between February 2013 and September 2015 in the Department of Psychiatry, University Hospital Centre Osijek, Croatia. A treating psychiatrist confirmed the diagnoses of the severe depressive episode without psychotic symptoms in major depressive disorder (MDD; F32.2) and bipolar disorder (BD-sDE; F31.4) according to ICD-10 (WHO 1992) diagnostic criteria and in consensus with two psychiatrists involved in this research. The patient group (patients with a severe depressive episode without psychotic symptoms with MDD or BD-sDE) sought urgent treatment due to a suicide attempt after which followed inpatient treatment. The control group consisted of inpatients admitted due to worsening of depressive symptoms within their MDD or BD-sDE, and who had no previous or current suicidal attempts. Within 72 hours upon admittance, patients who had suicide attempt and non-suicidal patients were approached by a psychiatrist and one's who agreed to participate were asked to complete the self-report questionnaire for assessment of personality. No further subsequent participation was needed. We assessed entire sample using a semistructured sociodemographic data form based on clinical experience and investigation of the available literature (Croatian Bureau of Statistics and Croatian Institute of Public Health). This study did not include the use of structured clinical interviews; therefore, comorbid psychiatric or personality diagnoses were not determined. From the study were excluded patients with mental retardation, schizophrenia and other psychotic disorders, alcohol and drugabuse related disorders, dementia and cognitive disorders, anxiety disorders and neurological disorders with unique personality features such as Parkinson's disease, multiple sclerosis, epilepsy, migraine, as well as some systemic disorders which may influence or are leading to cognitive impairment. After a detailed explanation of the study procedures, verbal and written informed consent was obtained from all the subjects. The study was officially approved by local Ethical Committee of the institution in which the study was conducted. Personality dimensions were assessed using the Temperament and Character Inventory (TCI version 9) a 240-item self-reported questionnaire with true-or-false statements. The TCI consists of seven higher-order scales based on psychobiological personality model. There are four temperament traits (NS, HA, RD, and PS) and three character traits (SD, CO, and ST). Suicidality was assessed based on current suicidal attempt through clinical assessment and examination and diagnosed according to ICD-10 (Category: External causes of morbidity and mortality; Sub-category: Intentional SelfHarm; X60-X85; WHO 1992) diagnostic criteria by attending psychiatrist.

\section{Statistical Analysis}

The data in this research were described using descriptive statistical methods (means, percentages, and standard deviations). The Mann-Whitney U-test was used to compare temperament and character dimensions in the samples (patient and control group). The Chisquare test, Student T-test and Fisher's exact test were used for assessment of differences between sociodemographic characteristics in both sample groups. The level of significance was set at P of 0.05 . All the statistical analyses were performed using the SPSS version 17.0 (SPSS Inc., Chicago, IL, USA).

\section{RESULTS}

The sample consisted of 30 (49\%) patients who had suicide attempt diagnosed with the major depressive disorder (MDD) - severe depressive episode without psychotic symptoms (F32.2), 31 (51\%) who had suicide attempt diagnosed with bipolar disorder - severe depressive episode without psychotic symptoms (BD$\mathrm{sDE})$. In the group of suicide attempters, there was 39 (64\%) females and $22(64 \%)$ of males. The non-suicidal group comprised of $20(35 \%) \mathrm{MDD}$ and $38(65 \%)$ of BD-sDE of whom $42(76 \%)$ were female and $16(28 \%)$ male patients. The mean age of the sample was 45 years ( $\mathrm{SD}=7.9$ years). The average duration of an overall psychiatric treatment was 7.9 years $(\mathrm{SD}=3.9$ years). The group with $\mathrm{BD}-\mathrm{sDE}(\mathrm{N}=52)$ had significantly more patients with current suicide attempt than the group with $\operatorname{MDD}\left(\chi^{2}\right.$ test, $\left.p=0.040\right)$. From a sociodemographic perspective of the sample, $9(8 \%)$ participants had completed elementary school, $78(66 \%)$ had completed high school, $16(13 \%)$ had completed vocational college and $16(13 \%)$ had a college degree. Regarding employment, $31(27 \%)$ od participants were employed, 50 (42\%) were unemployed, 26 (22\%) had seasonal jobs, and $11(9 \%)$ were retired. Regarding the financial status, 74 (62\%) participants had monthly income less than $2000 \mathrm{kn}$ (currency Croatian kuna=kn), 22 (18\%) had monthly income between $2000-3000 \mathrm{kn}, 15$ (13\%) had monthly income between $3000-5000 \mathrm{kn}$ and 8 (7\%) had monthly income between 5000-10000 kn. According to data regarding family history in the sample, $49(41 \%)$ of participants had a family member who was in psychiatric treatment, $31(26 \%)$ had a family member who committed suicide and 39 (33\%) had no family members who underwent psychiatric treatment nor committed suicide (Table 1). Initially, the sample was divided into two groups of patients. The group of patients who had suicidal attempt and nonsuicidal group. The participants who exhibited suicide attempt had significantly higher scores in HA $(p<0.001)$ 
Table 1. Sociodemographic factors of the sample

\begin{tabular}{|c|c|c|c|c|}
\hline & \multicolumn{3}{|c|}{ Number of $(\%)$ participants } & \multirow[b]{2}{*}{$\mathrm{p}^{*}$} \\
\hline & $\begin{array}{c}\text { Suicide } \\
\text { attempt group }\end{array}$ & $\begin{array}{l}\text { Non-suicdal } \\
\text { group }\end{array}$ & Total & \\
\hline Mood disorders & & & & 0.137 \\
\hline Major depressive episode - without psychotic symptoms & $30(49)$ & $20(35)$ & $50(42)$ & \\
\hline $\begin{array}{l}\text { Bipolar disorder - severe depressive episode } \\
\text { without psychotic symptoms }\end{array}$ & $31(51)$ & $38(65)$ & $69(58)$ & \\
\hline Gender & & & & 0.334 \\
\hline Male & $22(36)$ & $16(28)$ & $38(32)$ & \\
\hline Female & $39(64)$ & $42(72)$ & $81(68)$ & \\
\hline Age (years) $($ Mean \pm SD) & $44.7 \pm 8.1$ & $45.2 \pm 7.8$ & $45 \pm 7.9$ & $0.774^{\dagger}$ \\
\hline Level of education & & & & 0.550 \\
\hline Elementary school & $5(8)$ & $4(7)$ & $9(8)$ & \\
\hline High school & $43(70)$ & $35(60)$ & $78(66)$ & \\
\hline University & $7(11)$ & $9(16)$ & $16(13)$ & \\
\hline College & $6(10)$ & $10(17)$ & $16(13)$ & \\
\hline Level of employment & & & & 0.004 \\
\hline Employed & $10(16)$ & $22(38)$ & $32(27)$ & \\
\hline Unemployed & $35(57)$ & $15(26)$ & $50(42)$ & \\
\hline Seasonal work & $11(18)$ & $15(26)$ & $26(22)$ & \\
\hline Retired & $5(8)$ & $6(10)$ & $11(9)$ & \\
\hline Monthly income & & & & 0.116 \\
\hline Less than $2000 \mathrm{kn}$ & $44(72)$ & $30(52)$ & $74(62)$ & \\
\hline From 2000 to $3000 \mathrm{kn}$ & $9(15)$ & $13(22)$ & $22(18)$ & \\
\hline From 3000 to $5000 \mathrm{kn}$ & $6(10)$ & $9(16)$ & $15(13)$ & \\
\hline From 5000 to $10000 \mathrm{kn}$ & $2(3)$ & $6(10)$ & $8(7)$ & \\
\hline Duration of psychiatric treatment (years) $($ Mean $\pm S D)$ & $8.1 \pm 3$ & $7.7 \pm 3.9$ & $7.9 \pm 3.9$ & $0.559^{\dagger}$ \\
\hline Living circumstances & & & & 0.298 \\
\hline In the apartment & $15(25)$ & $12(21)$ & $27(23)$ & \\
\hline In the house & $7(11)$ & $15(26)$ & $22(18)$ & \\
\hline With parents & $13(21)$ & $8(14)$ & $21(18)$ & \\
\hline With parents and my family & $7(11)$ & $8(14)$ & $15(13)$ & \\
\hline As sub-tenant & $19(31)$ & $15(26)$ & $34(29)$ & \\
\hline Marital status & & & & 0.732 \\
\hline Single & $9(15)$ & $8(14)$ & $17(14)$ & \\
\hline Married & $27(44)$ & $24(41)$ & $51(43)$ & \\
\hline In a relationship & $9(15)$ & $9(16)$ & $18(15)$ & \\
\hline Widowed person & $3(5)$ & $7(12)$ & $10(8)$ & \\
\hline Divorced & $13(21)$ & $10(17)$ & $23(19)$ & \\
\hline Family history (anamnesis) & & & & 0.870 \\
\hline Family member in psychiatric treatment & $25(41)$ & $24(41)$ & $49(41)$ & \\
\hline Family member commited suicide & $17(28)$ & $14(24)$ & $31(26)$ & \\
\hline $\begin{array}{l}\text { No family members in psychiatric treatment/ } \\
\text { nor commited suicide in family }\end{array}$ & $19(31)$ & $20(34)$ & $39(33)$ & \\
\hline Total & $61(100)$ & $58(100)$ & $119(100)$ & \\
\hline
\end{tabular}

${ }^{*} \chi^{2}$ test; ${ }^{\dagger}$ Student T-test; ${ }^{\dagger}$ Fisherov egzact test

and significantly lower score in PS $(\mathrm{p}=0.037)$ temperament dimensions. In character dimensions, the patients with suicidal attempt had significantly lower scores on SD $(p<0.001)$ and significantly lower scores on CO $(p=0.001)$. The non-suicidal BD-sDE group had significantly lower scores on HA $(p=0.001)$ and significantly higher scores on NS $(\mathrm{p}=0.003)$, SD $(\mathrm{p}<0.001)$ and ST $(\mathrm{p}<0.001)$ subscales (Table 2$)$. Within the MDD group, the participants who attempted suicide had significantly higher scores on HA $(p<0.001)$ with significantly lower scores on NS $(p<0.001)$ and SD $(p=0.042)$. In the group with BD-sDE, participants who attempted suicide had statistically significant higher scores on NS $(\mathrm{p}=0.001)$ and significantly lower scores on PS $(\mathrm{p}=0.003)$, SD $(\mathrm{p}<0.001)$ and $\mathrm{CO}(\mathrm{p}=0.001)$ (Table 3$)$. The majority of patients who had suicidal attempt used non-violent methods. Them 28 (45.9\%), used the method of deliberate self-poisoning with antiepileptics, sedative-hypnotics, antiparkinsonian and psychotropic medications (X61.0; according to ICD-10). The 16 (26.2\%) of participants, attempted suicide with deliberate selfpoisoning with other and unspecified drugs, medicinal and biological substances (X64.0; according to ICD-10). There were no statistically significant differences between 
Table 2. Scores of temperament and character dimensions according to patient groups

\begin{tabular}{|c|c|c|c|c|}
\hline & \multicolumn{3}{|c|}{ Median (25\%-75\%) } & \multirow{2}{*}{$\mathrm{p}^{*}$} \\
\hline & Suicide attempt group & Non-suicidal group & Total & \\
\hline Harm Avoidance (HA) & $72.6(63.8-77.1)$ & $63.1(59.03-68.2)$ & $66.8(60.9-74.1)$ & $<0.001$ \\
\hline Novelty Seeking (NS) & $44.5(37.8-53.65)$ & $47(40.78-53.23)$ & $44.5(39.5-52.8)$ & 0.319 \\
\hline Reward Dependence (RD) & $42(35.2-46.6)$ & $39.8(35.2-48.9)$ & $42(35.2-46.6)$ & 0.972 \\
\hline Persistence (PS) & $36.3(31.1-41.6)$ & $37(35-4.6)$ & $36.3(31.1-41.6)$ & 0.037 \\
\hline Self-Directedness (SD) & $35.7(29.75-41.75)$ & $41.1(35.7-45.43)$ & $38.4(31.7-43.7)$ & $<0.001$ \\
\hline Cooperativeness (CO) & $35.7(31.5-39.2)$ & $39.9(33.95-44.35)$ & $37.1(32.9-42.6)$ & 0.001 \\
\hline \multirow[t]{2}{*}{ Self-Transcedence (ST) } & $40.2(33.8-44.9)$ & $38.6(33.8-44.9)$ & $40.2(33.8-44.9)$ & 0.628 \\
\hline & $\begin{array}{l}\text { Major depressive disorder- } \\
\text { severe depresive episode }\end{array}$ & $\begin{array}{c}\text { Bipolar disorder-severe } \\
\text { depressive episode }\end{array}$ & & \\
\hline Harm Avoidance (HA) & $73.35(62.4-77.1)$ & $65.3(59.4-69.7)$ & $66.8(60.9-74.1)$ & 0.001 \\
\hline Novelty Seeking (NS) & $41.2(37.8-51.2)$ & $47.8(42-54.5)$ & $44.5(39.5-52.8)$ & 0.003 \\
\hline Reward Dependence (RD) & $40.9(33-48.9)$ & $42(37.5-46.6)$ & $42(35.2-46.6)$ & 0.554 \\
\hline Persistence (PS) & $36.3(36.3-41.6)$ & $36.3(31.1-41.6)$ & $36.3(31.1-41.6)$ & 0.075 \\
\hline Self-Directedness (SD) & $42.4(37.1-45.1)$ & $35.7(30.4-41.75)$ & $38.4(31.7-43.7)$ & $<0.001$ \\
\hline Cooperativeness (CO) & $38.5(32.9-41.2)$ & $35.7(32.9-42.6)$ & $37.1(32.9-42.6)$ & 0.648 \\
\hline Self-Transcedence (ST) & $41.7(38.2-46.5)$ & $35.4(32.2-42.5)$ & $40.2(33.8-44.9)$ & $<0.001$ \\
\hline
\end{tabular}

*Mann Whitney U test

Table 3. The scores of temperament and character dimensions according to suicide attempters and non-suicidal patients in the groups of patients with major depressive disorder or with bipolar disorder

\begin{tabular}{lcccr}
\hline & \multicolumn{3}{c}{ Median (interquartile range) } & \multirow{2}{*}{ * } \\
\hline Major depressive disorder-severe depressive episode & Non-suicidal group & \multicolumn{1}{c}{} \\
Harm Avoidance (HA) & $76.35(74.1-78.5)$ & $62.4(58.28-66.43)$ & $73.35(62.4-77.1)$ & $<0.001$ \\
Novelty Seeking (NS) & $38.65(35.78-44.5)$ & $53.65(44.05-57.4)$ & $41.2(37.8-51.2)$ & $<0.001$ \\
Reward Dependence (RD) & $44.3(34.65-49.45)$ & $35.2(31.28-46.6)$ & $40.9(33-48.9)$ & 0.070 \\
Persistence (PT) & $37(35.18-46.8)$ & $36.3(36.3-41.6)$ & $36.3(36.3-41.6)$ & 0.734 \\
Self-Directedness (SD) & $40.4(35.38-44.05)$ & $43.7(39.08-46.4)$ & $42.4(37.1-45.1)$ & 0.042 \\
Cooperativeness (CT) & $38.5(32.2-41.2)$ & $38.5(33.25-43.65)$ & $38.5(32.9-41.2)$ & 0.138 \\
Self-Transcedence (ST) & $40.2(37-43.7)$ & $44.9(39-51.3)$ & $41.7(38.2-46.5)$ & 0.051 \\
Bipolar disorder-severe depressive episode & & & \\
Harm Avoidance (HA) & $65.3(59.4-71.2)$ & $63.8(59.03-69.7)$ & $65.3(59.4-69.7)$ & 0.502 \\
Novelty Seeking (NS) & $52.8(44.5-61.2)$ & $45.35(39.08-51.2)$ & $47.8(42-54.5)$ & 0.001 \\
Reward Dependence (RD) & $42(35.2-46.6)$ & $44.3(37.5-49.45)$ & $42(37.5-46.6)$ & 0.134 \\
Persistence (PT) & $36.3(31.1-36.3)$ & $38.95(31.1-46.8)$ & $36.3(31.1-41.6)$ & 0.003 \\
Self-Directedness (SD) & $31.7(29.1-35.7)$ & $39.7(34.08-45.1)$ & $35.7(30.4-41.75)$ & $<0.001$ \\
Cooperativeness (CT) & $34.3(31.5-38.5)$ & $40.55(33.95-45.4)$ & $35.7(32.9-42.6)$ & 0.001 \\
Self-Transcedence (ST) & $37(30.6-46.5)$ & $34.6(32.2-40.58)$ & $35.4(32.2-42.5)$ & 0.573 \\
\hline
\end{tabular}

*Mann Whitney U test

females and males in methods used for a suicide attempt. Of total 14 (46.7\%) participants who attempted suicide according to diagnostic criteria X61.0, there were significantly more female patients in the group of MDD (Fisher exact test, $\mathrm{p}=0.028$ ). In the group of patients who had suicide attempt with BD-sDE, there were no statistically significant differences by sex.

\section{DISCUSSION}

The goal of this study was to determine specific personality traits, measured with TCI, among patients with recent suicide attempt during the severe depressive episode without psychotic symptoms in MDD and BD$\mathrm{sDE}$. However, the emphasis in this research was to find those particular personality features during an acute phase of illness (MDD or BD-sDE) referring to a period immediately after a suicide attempt. We found that patients who had recent suicide attempt during the depressive episode of a mood disorder (respectively, MDD or BD-sDE) presented with different personality profile than the non-suicidal control group. In the group of suicide attempters, we found significantly higher scores on HA and significantly lower scores in SD, CO, and PS when compared to the non-suicidal group. Previous studies found results somewhat similar to ours, 
i.e., higher HA and lower SD in the group of patients with mood disorders who had suicide attempt (see Woo et al. 2014, Brezo et al. 2006, Engstrom et al. 2004). Higher HA, defined as a tendency to respond intensely to signals or aversive stimuli, may be state-dependent personality trait in depressive states (Pelissolo \& Corruble 2002). This particular temperament trait could be observed from several aspects. Therefore, relatively high HA is often correlated with the severity, duration or remission of depressive states although one study questioned that state-dependency of HA and postulated it as a stable component not solely as a manifestation of mood (see Ekinci et al. 2012). Likewise, HA, according to Cloninger's neurobiological model, is highly heritable temperament dimension linked to the serotonergic system (see Pelissolo \& Corruble 2002). Dysfunction of the serotonergic system was found to have a significant role in the neurochemistry and genetics of suicidal behavior (Ebstein 2006, Peirson et al. 1999). These complex heritable, neurobiological and psychopathological interconnections undoubtedly accentuate the HA as a temperament trait with the particular role in suicidal behavior and mood disorders. This could explain why high scores in HA dimension were found in both suicidal and non-suicidal group of this research. However, we can not discrimnate whether these high scores are due to primary personality traits, state-dependent (influence of depressive episode) or appoint to suicidal behavior. Different studies also had consistent findings regarding on personality features in mood disorders regarding low SD and its association with depression. Self-directedness, as a character trait, encompasses personality features like responsibility, self-acceptance, effectiveness. Adversely, low SD has been associated with immaturity, destructiveness, poor self-integration, ineffective (see Cloninger et al. 1994). Therefore, experience of a depressive episode may have adverse consequences for maturation of this character feature leading to immature self-concept which is a vulnerability factor for negative affect in general (Matsudaira \& Kitamura 2005). Low self-directedness (SD), besides its relation to depressive states, is also related to suicidality. Our results are accordant to previous studies that reported lower SD scores among suicide attempters compared with non-attempters (Becerra et al. 2005, Grucza et al. 2005). In the overall sample, we did not find any significant differences in NS, RD, and ST between the group of suicide attempters and nonsuicidal group. The NS dimension was found be higher in the both patient groups, but slightly, albeit not significantly, higher in the non-suicidal group. Studies regarding other temperament dimensions $(\mathrm{NS}, \mathrm{CO}$, and PS) have heterogeneous findings. It has been proposed that this is probably related to sample size, study methodology, patient selection and severity of suicidal attempt (Perroud et al. 2013, Kampman et al. 2012, see Kampman et al. 2011). Our findings in the group of suicide attempters with severe depressive episode in bipolar disorder (BD-sDE) confirmed the results from several previous studies on higher scores of particular temperament dimensions: NS and HA, and lower scores on character dimensions SD, PS, CO (see Izci et al. 2016, Engstrom et al. 2003). Interestingly, in the previously mentioned group of patients and also in the group of suicide attempters in general, we found lower scores on SD and $\mathrm{CO}$ character dimensions. Some authors proposed that lower scores of these specific character dimensions may predict the development of personality disorder (Slama et al. 2004). These results were not present in the group of suicide attempters with a severe depressive episode in major recurrent depressive disorder where we found higher scores in $\mathrm{HA}$ and lower scores in NS and SD dimensions also confirmed in some previous studies (see Woo et al. 2014, see Conrad et al. 2009). In our study, the results in NS and PS scores opposite than HA scores may be perceived as clinically significant findings associated with depressive episode (see Kampman et al. 2012). As mentioned afore, the lower scores in SD and CO (i.e. in suicide attempters in BD-sDE and suicide attempters in the sample, in generally) could be the predictors of personality disorder, and this could also suggest that personality disorder may be more frequent in patients with bipolar disorder (Kessing 1998). We have also found, however not significantly, higher scores in ST character dimension in the group of suicide attempters with a severe depressive episode with bipolar disorder. These results are comparable with one's in previous studies due to association between high ST and suicidality, as high ST is associated with low SD which is earmarked by immature and illogical behavior (Aukst Margetic et al. 2011, Bulik et al. 1999). In the group of non-suicidal patients with a severe depressive episode of bipolar disorder, we found lower scores in HA when compared to the non-suicidal group with a severe depressive episode in recurrent major depressive disorder and higher scores on NS, SD, and ST. In comparison to previously mentioned results and studies, lower scores in HA and higher scores in NS, SD and ST may be interpreted as possibly sample specific or from the wider perspective, perceived as protective factors in this group of patients. According to some studies, the possible influence of sociodemographic factors and methods used for suicide attempt may not be disregarded (Stenbacka \& Jokien 2015, Mendlowicz et al. 2000). Our sample showed of high level of unemployment (42\% of all patients), low average monthly income (62\% of all patients) with predominantly non-violent methods of suicide attempts. This might have had some impact on the obtained results (low PS scores, heterogeneous scores in NS) in temperament and character dimensions in our research. Since we included baseline parameters in this study, the long-term associations between personality traits and clinical characteristics were not addressed. Some future research could thoroughly follow the course of mood disorders in these 
subjects and evaluate the personality features and their complex interrelations to suicidal behavior, sociodemographic properties as well as the impact of psychopharmacological interventions.

\section{Limitations of the study}

This study had some limitations such as sample size, sole use of self-report questionnaires, research methodology (lacking evidence from biological (i.e. genetic) methods), and potential impact of adverse sociodemographic factors which probably influenced our results and its interpretation when compared to some previous studies.

\section{CONCLUSION}

Patients who had suicide attempt may display some significantly different personality traits than nonsuicidal patients with mood disorders. The combination of high HA and low SD may be specific for depressive episode. The combination of high HA, NS, and ST with low SD may be related to suicide attempts in mood disorders, especially for depressive episode in bipolar disorder. The Temperament and Character Inventory could be helpful for detailed exploration of personality traits underlying suicidality and mood disorders.

\section{Acknowledgements: None.}

\section{Conflict of interest: None to declare.}

\section{Contribution of individual authors:}

Anamarija Petek Erić: study conception and design; aquisition of data; analysis and interpretation of data; drafting manuscript;

Ivan Erić: aquisition of data, drafting manuscript; critical revision;

Mario Ćurković: aquisition of data;

Katarina Dodig-Ćurković: aquisition of data; Kristina Kralik: analysis and interpretation of data; Vlatka Kovač: aquisition of data;

Pavo Filaković: critical revision.

\section{References}

1. Akiskal HS, Hirschfield RM \& Yerevenian BI: The relationship of personality to affective disorders. Arch Gen Psychiatry 1983; 40:801-10.

2. Aukst Margetic B, Jakovljevic M, Ivanec D, Tosic G \& Margetic B: Novelty seeking and medication adherence in patients with schizohrenia. Psychiatry Res 2011; 186:141-43.

3. Becerra B, Paez F, Robles-Garcia $R$ \& Vela GE: Temperament anc character profile of persons with suicide attempt. Acta Esp Psiquiatr 2005; 33:117-22.

4. Brent DA \& Mann JJ: Family genetic studies, suicide, and suicidal behaviour. Am J Med Genet C Semin Med Genet 2005; 103C:13-24.
5. Brezo J, Paris $J$ \& Turecki G: Personality traits as correlates of suicidal ideation, suicide attempts, and suicide completions: a systematic review. Acta Psychiatr Scand 2006; 113:180-206.

6. Bulik CM, Sullivan PF \& Joyce PR: Temperament and character and suicide attempts in anorexia nervosa, bullimia nervosa and major depression. Acta Psychiatr Scand 1999; 100:27-32.

7. Calati R, Giegling I, Rujescu D, Hartmann AM, Möller HJ, De Ronchi $D$ et al: Temperament and character of suicide attempters. J Psychiatr Res 2008; 11:938-45.

8. Camarena B, Fresàn $A$ \& Sarmiento E: Exploring personality features in patients with affective disorders and history of suicide attempts: a comparative study with their parents and control subjects. Depress Res Treat 2014; 2014:291802 doi: 10.1155/2014/291802

9. Clemente AS, Diniz BS, Nicolato R, Kapczinski FP, Soares JC, Firmo JA et al: Bipolar disorder prevalence: a systematic review and meta-analysis of the literature. Rev. Bras. Psiquiatr 2015; 37:155-61.

10. Cloninger CR, Przybeck TR, Svrakic DM \& Wetzel RD: The temperament and Character Inventory (TCI). A Guide to Its Development and Use. Center for Psychobiology of Personality, Washington University, St Louis, Missouri, 1994.

11. Cloninger CR, Svrakic DM \& Przybeck TR: A psychobiological model of temperament and character. Arch Gen Psychiatry 1993; 50:975-90.

12. Connolly KR \& Thase ME: The Clinical Managment of Bipolar Disorder: A Review of Evidence-Based Guidelines. Prim Care Companion CNS Disord 2011; 13:1-74.

13. Conrad R, Walz F, Geiser F, Imbierowicz K, Liedtke R \& Wegener I: Temperament and character personality profile in relation to suicidal ideation and suicide attempts in major depressed patients. Psychiatry Res 2009; 170:212-17.

14. De Abreu LN, Lafer B, Baca-Garcia E \& Oquendo MA: Suicidal ideation and suicide attempts in bipolar disorder type I: an update for clinican. Rev Bras Psiquiatr 2009; 31:271-80.

15. Ebstein RP: The molecular genetic architecture of human personality: beyond self-report questionnaires. Mol Psychiatry 2006; 11:427-45.

16. Ekinci O, Yakup A \& Asli EE: Temperament and character in euthymic major depressive disorder patients: The effect of previous suicide attempts and psychotic mood episodes. Psychiatry Investig 2012; 9:119-26.

17. Engström C, Brandstörm S, Sigvardsson S, Cloninger CR \& Nylander PO: Bipolar disorders II. Bipolar Disord 2003; 5:340-48.

18. Engstrom C, Brandstrom S, Sigvardsson S, Cloninger CR \& Nylander PO: Bipolar disorder. III: Harm avoidance a risk factor for suicide attempts. Bipolar Disord 2004; 6:130-8.

19. Global Health Estimates 2013: Deaths by Cause, Age and Sex, Estimates for 2000-2012. Geneva: World Health Organization; 2014 (http://www.who.int/healthinfo/global_burden_disease/en/ accessed 10.10.2016.)

20. Grucza RA, Przybeck TR \& Cloninger CR: Personality as a mediator of demographic risk factors for suicide attempts in a community sample. Compr Psychiatry 2005; 46:214-22.

21. Harwitz D \& Ravizza L: Suicide and depression. Emerg Med Clin North Am 2000; 18:263-71.

22. Izci F, Findikli EK, Zincir S, Zincir SB \& Koc Mi: The differences in temperament-character traits, suicide attempts, impulsivity, and functionality levels of patients with bipolar disorder I and II. Neuropsychiatr Dis Treat 2016; 12:177-84. 
23. Jylhä PJ, Rosenström T, Mantere O, Souminem K, Melartin TK, Vuorilehto MS et al: Temperament and Character, and suicide attempts in unipolar and bipolar mood disorders. $J$ Clin Psychiatry 2016; 77:252-60.

24. Kampman $O \&$ Poutanen $O$ : Can onset and recovery in depression be predicted by temperament? A systematic review and meta-analysis. J Affect Disord 2011; 135:20-27.

25. Kampman O, Poutanen O, Illi A, Setälä-Soikkeli E, Viikki $M$, Nuolivirta $T$ et al: Temperament profiles, major depression and response to treatment with SSRI in psychiatric outpatients. Eur Psychiatry 2012; 27:245-49.

26. Karam EG, Itani L, Fayyad J, Hantouche E, Karam A et al: Temperament and suicide: A national study. J Affet Disord 2015; 184:123-28.

27. Kessing LV: Recurrence in affective disorder. Effect of age and gender. Br J Psychiatry 1998; 172:29-34.

28. Latalova K, Kamaradova D \& Prasko J: Suicide in bipolar disorder: a review. Psychiatr Danub 2014; 26:108-14.

29. Laursen TM: Life expectancy among persons with schizophrenia or bipolar affective disorder. Schizophr Res 2011; 131:101-04.

30. Mann JJ: The serotoninergic system in mood disorders and suicidal behaviour. Philos Trans $R$ Soc Lond B Biol Sci 2013; 368:20120537

31. Marangell LB, Bauer MS, Dennehy EB et al: Prospective predictors of suicide and suicide attempts in 1,556 patients with bipolar disorders followed up for up to 2 years. Bipolar Disord 2006; 8:566-75.

32. Matsudaira $T$ \& Kitamura T: Personality traits as risk factors of depression and anxiety among Japanese students. J Clin Psychol 2006; 62:97-109.

33. McAdams DP \& Bradley DO: Personality Development: Continuity and change over the life course. Annu Rev Psychol 2010; 61:517-42.

34. Mendlowicz MV, Jean-Louis G, Gillin JC, Akiskal HS, Furlanetto LM et al: Sociodemographic predictors of temperament and character. J Psychiatr Res 2000; 34:221-6.

35. Mental Health Action Plan 2013-2020. Geneva: World Health Organization; 2013 (http://apps.who.int/iris/ bitstream/10665/89966/1/9789241506021_eng.pdf, accessed 10.10.2016

36. Mental Health Atlas 2014. Geneva: World Health Organization; 2015 (http:// apps.who.int/iris/bitstream/10665/178879/1/978924156501 1_eng.pdf?ua=1\&ua=1, accessed 10.10.2016).

37. Pawlak J, Dmitrzak-Weglarz M, Skibińska M et al: Suicide attempts and psychological risk factors in patients with bipolar and unipolar affective disorder. Gen Hosp Psychiatry 2013; 35:309-13.

38. Pawlak J, Dmitrzak-Werglarz M, Maciukiewicz M, Kapelski P, Czerski P, Leszczynska-Rodziewicz A et al: Personality traits as an endophenotype in genetic studies on suicidality in bipolar disorder. Acta Neuropsychiatr 2016; 30:1-7.

39. Peirson AR, Heuchert JW, Thomala L, Berk M, Plein H \& Cloninger CR: Relationship between serotonin and temperament an character inventory. Psychiatry Res 1999; 89:29-37.
40. Pelissolo A \& Corruble E: Personality factors in depressive disoders: contribution of the psychobiologic model developed by Cloninger. Encephale 2002; 28:363-73.

41. Perroud N, Baud P, Ardu S et al: Temperament personality profiles and life processes associated with the onset of suicidal behaviour: an investigation of associated demographic, clinical and genetic factors. J Affect Disord 2013; 146:246-53.

42. Richter J, Eisemann $M \&$ Richter $G$ : Temperament and character during the course of unipolar depression among inpatients. Eur Arch Psychiatry Clin Neurosci 2000; 250:40-47.

43. Rihmer A, Rihmer Z, Jekkel $E$ et al: Psychiatric characteristics of 100 nonviolent suicide attempters in Hungary. Int J Psychiatry Clin Pract 2006; 10:69-72.

44. Rihmer Z: Suicide risk in mood disorders. Curr Opin Psychiatry 2007; 20:17-22.

45. Rudd MD, Berman AL, Joiner TE, Jr Nock MK, Silverman MM, Mandrusiak M, Van OK \& Witte T: Warning signs for suicide: theory, research, and clinical applications. Suicide Life Threat Behav 2006; 36:255-62.

46. Slama F, Bellvier F, Henry $C$ et al: Bipolar patients with suicidal behaviour: toward the identification of a clinical subgroup. J Clin Psychiatry 2004; 65:1035-39.

47. Sokero TP, Melratin TK, Rytsala HJ et al: Prospective study of risk factors for attempted suicide among patients with DSM-IV major depressive disorder. Br J Psychiatry 2005; 186:314-18.

48. Statham DJ, Heath AC, Madden PA et al: Suicidal behaviour: an epidemiological and genetic study. Psychol Med 1998; 28:839-855.

49. Stenbacka $M \&$ Jokien J: Violent and non-violent methods of attempted and completed suicide in Swedish young men: the role of early risk factors. BMC Psychiatry 2015; 15:196 doi: 10.1186/s12888-015-0570-2

50. Suominen K, Isometsa ET, Suokas $J$ et al: Completed suicide after a suicide attempt: a 37-year follow-up study. Am J Psychiatry 2004; 161:563-64.

51. Turecki G, Ernst C, Jollant F, Labonte B \& Mechawar N: The neurodevelopmental origins of suicidal behaviour. Trends Neurosci 2012; 35:14-23.

52. Undurraga J, Baldessarini RJ, Valenti M, Pacchiarroti I \& Vieta E: Suicidal risk factors in bipolar I and II disorder patients. Clin Psychiatry 2012; 73:778-82.

53. Woo YS, Jun TY, Jeon YH, Song HR, Kim TS et al: Relationship of Temperament and Character in Remitted Depressed Patients with Suicidal Ideation and Suicide Attempts - Results from the CRESCEND Study. PLoS ONE 2014; 9:e105860.

54. World Health Organization, World suicide prevention day 2012. http://www. who.int/mediacentre/events/annual/world_suicide_preventio $n$ day/en/Accessed 10.10.2016

55. Yutzy SH, Woofter CR, Abbott CC, Melhem IM \& Parish BS: The increasing frequency of mania and bipolar disorder: causes and potential negative impatcs. J Nerv Ment Dis 2012; 200:380-7.

\section{Correspondence:}

Anamarija Petek Erić, $M D, P h D$

Department of Psychiatry, University Hospital Centre Osijek

J. Huttler 4, 31000 Osijek, Croatia

E-mail:ana5ek@gmail.com 